\title{
Percutaneous endoscopic versus radiologic gastrostomy for enteral feeding: a retrospective analysis on outcomes and complications
}

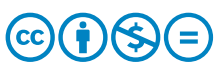

\author{
Authors \\ Denise Strijbos ${ }^{1,2}$, Daniel Keszthelyi ${ }^{1}$, Lennard P. L. Gilissen ${ }^{2}$, Martin Lacko ${ }^{3}$, Janneke G. J. Hoeijmakers ${ }^{4}$, Christiaan \\ van der Leij ${ }^{5}$, Rogier J. J. de Ridder ${ }^{1}$, Michiel W. de Haan ${ }^{5}$, Ad A. M. Masclee ${ }^{1}$
}

Institutions

1 Division of Gastroenterology and Hepatology, Department of Internal Medicine, NUTRIM School of Nutrition and Translational Research in Metabolism, Maastricht University Medical Center, Maastricht, The Netherlands

2 Department of Gastroenterology and Hepatology, Catharina Hospital Eindhoven, The Netherlands

3 Department of Otorhinolaryngology/Head \& Neck Surgery, Maastricht University Medical Center, Maastricht, The Netherlands

4 Department of Neurology, Maastricht University Medical Center, Maastricht, The Netherlands

5 Department of Radiology, Maastricht University Medical Center, Maastricht, The Netherlands

submitted 14.10 .2018

accepted after revision 7.2 .2018

Bibliography

DOI https://doi.org/10.1055/a-0953-1524 |

Endoscopy International Open 2019; 07: E1487-E1495

(c) Georg Thieme Verlag KG Stuttgart · New York elSSN 2196-9736

Corresponding author

Denise Strijbos, Maastricht University Medical Center, P. Debyelaan 25, 6229 HX, Maastricht, the Netherlands Fax: $+31(0) 402399751$ denise.strijbos@catharinaziekenhuis.nl

Supplementary material

Online content viewable at:

https://doi.org/10.1055/a-0953-1524

\section{ABSTRACT}

Background and study aims Percutaneous endoscopic gastrostomy (PEG) and percutaneous radiologic gastrostomy (PRG) are techniques used for long-term enteral feeding. Our primary aim was to analyze procedure-related and 30-day mortality and complications between PEG and PRG in relation to indications.

Patients and methods A single-center retrospective analysis was performed thath included all adult patients receiving initial PEG (January 2008 until April 2016) and PRG (January 2010 until April 2016). Outcomes were mortality (procedure-related, 30-day), complications (early ( $\leq 30$ days) and late) and success rates.

Results A total of 760 procedures (469 PRG and 291 PEG) were analyzed. Most common indications were head and neck cancer (HNC), cerebrovascular accident (CVA) and amyotrophic lateral sclerosis (ALS). Success rates for placement were $91.2 \%$ for PEG and $97.1 \%$ for PRG $(P=0.001)$. Procedure-related mortality was $1.7 \%$ in PEG and $0.4 \%$ in PRG $(P=0.113)$. The 30 -day mortality was $10.7 \%$ in PEG and $5.1 \%$ in PRG ( $P=0.481$ after multivariate logistic regression) CVA was associated with higher 30-day mortality, whereas ALS, higher body weight, and prophylactic placements in HNC were associated with lower rates.

Tube-related complications were less frequent in PEG, both early $(2.7 \%$ vs. $26.4 \%, P \leq 0.001)$ and late $(8.6 \%$ vs. $31.5 \%$, $P \leq 0.001)$. The percentage of major complications and infections did not differ.

Conclusions With respect to procedure-related and 30day mortality, PEG and PRG compare equally. PRG had a higher procedural success rate. Tube-related complications and pain are less frequent after PEG compared to PRG. The choice for either PEG or PRG therefore should primarily be based on local facilities and expertise.

\section{Introduction}

Gastrostomy is the method of choice for enteral feeding that is expected to last longer than 4 weeks (medium- and long-term enteral feeding) [1,2]. Available gastrostomy techniques in- clude percutaneous endoscopic gastrostomy (PEG) and percutaneous radiologic gastrostomy (PRG). PEG was developed in 1980 by Gauderer et al. Shortly afterwards, Preshaw et al. developed a radiologic alternative [3]; PRG, also called fluoroscopy-guided gastrostomy (FPG) or radiologically inserted gastros- 
tomy (RIG). Both techniques are preferred over surgical gastrostomy due to lower morbidity rates $[1,4,5]$.

Main indications for gastrostomy placement include dysphagia or swallowing dysfunction, caused by neurological disorders (cerebral vascular accidents [CVA], amyotrophic lateral sclerosis [ALS]), malignancies (esophageal, head and neck cancer $[\mathrm{HNC}])$, malnutrition and motility disturbances of the upper gastrointestinal tract $[1,2]$. Patients receiving a PRG or PEG are characterized by poor condition due to malnutrition and underlying disease. Therefore, complications of PEG or PRG placement are likely to have a major impact on prognosis and outcome.

Consensus on which technique/route should be preferred as access for enteral feeding, with respect to safety, success rates, complications, and availability, has not yet been reached.

Previous reports on this topic are of limited value due to small sample sizes and high risk of confounding and selection bias [6-13]. These studies suggest that both techniques are comparable in terms of morbidity and mortality $[6,14,15]$. Dislocation, obstruction, and other tube-related complications appear to occur more often in PRG. Peristomal infections more frequently occur in PEG. For this reason, antibiotic prophylaxis is now recommended to lower this risk, resulting in a risk reduction from $24.2 \%$ to $8.4 \%$ [16]. Because the tube is not pulled through the oropharynx cavity in PRG, transfer of oropharyngeal microbiota more distally is avoided. Risk of infection is therefore assumed to be lower (around $0.3 \%$ to $7 \%$ without antibiotics [17]) and routine administration of antibiotics in PRG procedures is not recommended.

An advantage of PRG is that the procedure is generally performed without sedation (in contrast to PEG) and that PRG can also be placed in cases of esophageal stenosis or (malignant) esophageal/oropharyngeal obstruction [18]. Tumor seeding to the stoma site is a feared complication of PEG, with 49 reported cases currently in the literature, whereas one case of tumor seeding has been described after PRG [19-21].

In our center, both PEG and PRG are available and used on a regular basis. Choice of one of the two techniques is empirical and primarily based on the referring physician's past experience and preferences. In general, patients with ALS and HNC are referred exclusively for PRG due to fear of sedation-related complications and tumor seeding, respectively (for more detail, see Supplementary File 1 ).

Our primary aim was to retrospectively analyze data from our center with respect to procedure-related and 30-day mortality and complications of PEG and PRG procedures in relation to indications and to compare PEG and PRG results. These data may help to better predict which technique may serve as best option for an individual patient.

\section{Patients and methods}

Data from all adult patients receiving initial PRG (January 2010 until April 2016) and PEG or PEG-J (January 2008 until April 2016) placement at the Maastricht University Medical Center, a tertiary referral center, were retrospectively analyzed. Patients with PEG placements with additional duodenal/jejunal extension were included in the PEG group. Data from PRGs prior to 2010 were not available. PEGs from 2008 and 2009 were included to create a sample size comparable to PRG. In case of incomplete follow-up data, patients were excluded from the analysis.

\section{Procedure}

Prior to gastrostomy placement, oral anticoagulants were temporarily stopped (preferable international normalized ratio [INR] $<1.5$ in case of vitamin $\mathrm{K}$ antagonists) for 2 to 5 days, as well as thienopyridines (for 5 to 7 days). Use of acetylsalicylic acid was allowed.

\section{PEG}

Conscious sedation using midazolam (low-dose, mean $2.5 \mathrm{mg}$ ) and a fast-acting opioid was administered. Oral amoxicillin/clavulanic acid $1200 \mathrm{mg}$ was given 30 minutes before the procedure (in case of allergy, a substitute was given). PEG (Freka PEG, 15Fr, Fresenius Kabi AG, Bad Homburg, Germany) placement was performed according to the standard Pull-method as first performed by Gauderer et al [22]. In several cases $(n=26)$, a jejunal extension tube was placed through the PEG tube, and pulled distally from the papilla of Vater with a grasping forceps. Afterwards, patients were observed for at least 1 hour at the day care unit. Immediately after placement, water was administered through the tube. Feeding was started the next day.

\section{PRG}

PRG placement was performed according to standard placement described by Preshaw [3] using a Wills-Oglesby Percutaneous Gastrostomy Set (12Fr, Cook, Bloomington, Indiana, United States).

Neither standard prophylactic antibiotics nor sedatives were given. Only local anesthetics were administered at the puncture site. Before the procedure, using ultrasound, the location of the stomach as well as any possible interposing organs (left liver lobe, (transverse) colon, small bowel) was checked. After intravenous injection of $20 \mathrm{mg}$ of buscopan, the stomach was inflated using a nasogastric tube placed inside the stomach before the procedure. After local anesthesia with $20 \mathrm{~mL}$ to $30 \mathrm{~mL}$ of $1 \%$ lidocaine, the stomach was punctured under fluoroscopic (and sometimes ultrasound) guidance to place the anchors. In total three anchors were placed in a triangular orientation. Intragastric position of the needle was confirmed using a small amount of contrast material. After fixation of the three anchors, the stomach was punctured centrally between the anchors, and a guidewire inserted. After dilatation of the tract, the gastric tube was placed over the wire. The day after placement, saline fluids were administered through the tube for 3 to 6 hours. Feeding was started thereafter and the patient was discharged. Ten to 14 days after the procedure, patients returned to the radiology department to remove the anchors.

\section{Data collection}

Baseline data collected from medical records were gender, age, body mass index (BMI) before tube placement, weight loss before gastrostomy placement, indication for tube placement, 
significant comorbidities (chronic cardiac, pulmonary, kidney, gastrointestinal and liver diseases, malignancies and diabetes mellitus [DM]).

Retrospectively, all patient files, including endoscopic and radiologic reports, were reviewed to ascertain whether any complications had occurred during follow-up (maximum 6 years), including death. Inclusion and exclusion criteria for PEG and PRG are shown in $>$ Fig. 1.

\section{Outcome measures}

The primary outcome measure was mortality (30-day and procedure-related [defined as mortality occurring due to a complication of the procedure]). Secondary outcomes were occurrence of complications, early (<30 days) and late, scored as minor or major [1,2], and procedure success rates. Complications were analyzed according to the international CIRSE, AGA and ESPEN classification 1,2,23], and divided into early and late complications ( $\leq 30$ days, and $>30$ days), as well as severity: mi-
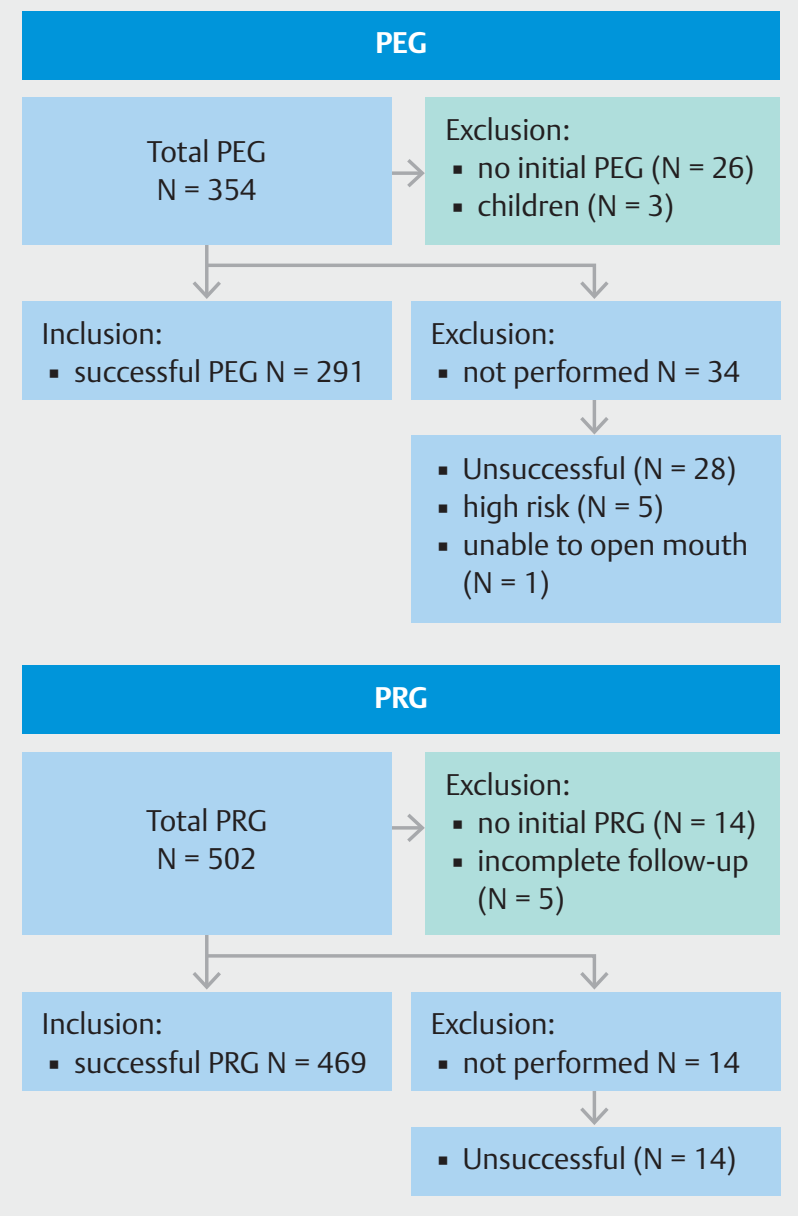

- Fig. 1 Flowchart of all PEG and PRG patients showing criteria for inclusion and exclusion.

*Not first PEG/PRG: Multiple gastrostomy procedures Unsuccessful procedure: due to absence of transillumination, intrathoracic position of stomach, colon interposition High risk: presence of ascites or estimated high risk for tumor seeding nor (requiring conservative treatment) or major. Infection was classified as erythema, pain, and/or purulent discharge, requiring antibiotic treatment (as diagnosed by expert clinical opinion). Dislocation, obstruction, leakage and tube/balloon defects were reported combined, as "tube-related complications". PRG tubes were preventively replaced after 3 to 6 months, through the existing fistula channel. These scheduled replacements were not scored as complications. PEG tubes or PEG tubes with a jejunal extension (PEG-j) tubes were not routinely replaced.

\section{Statistical analysis}

Data analysis was performed using SPSS for Windows, version 23 (IBM Corporation). Statistical methods are described in Supplementary File 1.

\section{Ethical considerations}

This study was approved by the Medical Research Ethics Committee of the Maastricht University Medical Center. The study was conducted according to the Dutch Codes of Conduct.

\section{Results}

In total, 856 patient files (502 PRG, 354 PEG) matching our search criteria were found.

The patient inclusion flowchart is presented in $\mathbf{F i g . 1}$. The difference in procedural success rates-91.2\% for PEG (291/ $319)$ and $97.1 \%$ for PRG ( $n=469 / 483)$-was statistically significant $(P=0.001)$. Various reasons account for failure of placement. In PEG, these included the inability to obtain transillumination ( $41 \%$ of failed cases, $n=14$ ), stenosis ( $26 \%, n=9$ ), an intrathoracic position of the stomach $(15 \%, n=5)$. In addition, PEG placement was not performed due to presence of highrisk factors such as ascites $(15 \%, n=5)$ or inability of a patient to adequately open his mouth $(3 \%, n=1)$.

Inability to puncture the stomach was the most frequent factor for failure of PRG placement ( $n=8,57 \%$ of failed cases). This was either related to previous surgery (Billroth II stomach, $n=3,21 \%)$, or was due to a too painful procedure $(21 \%, n=3)$. In case of PEG failure, PRG placement was successfully performed in eight cases. PEG after PRG failure was successfully performed in three patients.

Certain conditions such as ascites or previous partial gastrectomy are in fact contraindications for PEG or PRG placement. When these cases were excluded, the success rate for PEG placement was $92.9 \%$, which is still significantly lower than in case of PRG $(97.7 \%, P=0.001)$.

A total of 760 successful procedures (469 PRG and 291 PEG) were included in the analysis (62.9\% male, mean age $62.8 \mathrm{yrs}$ [SD 12.64]). Baseline characteristics are shown in $>$ Table 1 (an extended list of comorbidities can be found in Supplementary Table 1).

\section{0-day mortality}

The 30-day mortality was significantly different between the procedures, with a mortality rate of $10.7 \%$ in the PEG group vs. $5.1 \%$ in the PRG group $(P=0.005$, OR 2.214 [1.263- 
- Table 1 Baseline characteristics of patients who underwent PEG or PRG at Maastricht UMC between 2008 and 2016.

\begin{tabular}{|c|c|c|c|}
\hline Parameters & $\begin{array}{l}\text { PEG N (\%*) } \\
\text { (total } \\
n=291 \text { ) }\end{array}$ & $\begin{array}{l}\text { PRG N (\%*) } \\
\text { (total } \\
n=469)\end{array}$ & $P$ value \\
\hline Male & $173(59,5 \%)$ & $305(65 \%)$ & 0.208 \\
\hline \multicolumn{4}{|l|}{ Age (yrs) } \\
\hline - Range & $20-90$ & $22-72$ & \multirow[t]{2}{*}{0.306} \\
\hline - Mean [SD] & $\begin{array}{l}63,38 \\
{[10,97]}\end{array}$ & $\begin{array}{l}62,41 \\
{[14,94]}\end{array}$ & \\
\hline \multicolumn{4}{|l|}{ Weight loss before (kg) } \\
\hline - Range & $0-42 \mathrm{~kg}$ & $0-34 \mathrm{~kg}$ & \multirow[t]{2}{*}{0.023} \\
\hline - Mean [SD] & $\begin{array}{l}4,17 \\
{[6,281]}\end{array}$ & $\begin{array}{l}4,99 \\
{[6,364]}\end{array}$ & \\
\hline \multicolumn{4}{|l|}{ BMI before (kg/m2) } \\
\hline - Mean [SD] & $\begin{array}{l}23,61 \\
{[13,09]}\end{array}$ & $\begin{array}{l}22,19 \\
{[4,60]}\end{array}$ & 0.120 \\
\hline \multicolumn{4}{|l|}{ Diagnosis } \\
\hline $\begin{array}{l}\text { Amyotrophic lateral } \\
\text { sclerosis }\end{array}$ & $8(2.7)$ & $46(9.8)$ & $<0.001$ \\
\hline $\begin{array}{l}\text { Cerebrovascular } \\
\text { accident }\end{array}$ & $40(13.7)$ & $10(2.1)$ & $<0.001$ \\
\hline Cystic fibrosis & $4(1.4)$ & $2(0.4)$ & 0.210 \\
\hline $\begin{array}{l}\text { Gastrointestinal } \\
\text { motility disorder }\end{array}$ & $19(6.5)$ & $0(0)$ & $<0.001$ \\
\hline $\begin{array}{l}\text { Head/neck malignan- } \\
\text { cy (total, including } \\
\text { prophylactic) }\end{array}$ & $113(38.8)$ & $328(69.9)$ & $<0.001$ \\
\hline $\begin{array}{l}\text { Head/neck malignan- } \\
\text { cy (prophylactic } \\
\text { placements only) }\end{array}$ & $66(22.6)$ & $294(62.6)$ & $<0.001$ \\
\hline $\begin{array}{l}\text { Long-term enteral } \\
\text { feeding, disorder not } \\
\text { specified }\end{array}$ & $21(6.7)$ & $9(1.9)$ & 0.001 \\
\hline $\begin{array}{l}\text { Malignancy not in } \\
\text { head/neck region }\end{array}$ & $21(7.2)$ & $18(3.8)$ & 0.398 \\
\hline Muscular disease & $11(3.8)$ & $15(3.2)$ & 0.668 \\
\hline $\begin{array}{l}\text { Neurological disease, } \\
\text { (including multiple } \\
\text { sclerosis, Parkinson's } \\
\text { disease) }\end{array}$ & $41(14)$ & $13(2.7)$ & $<0.001$ \\
\hline $\begin{array}{l}\text { Postsurgical/trauma- } \\
\text { tic swallowing dys- } \\
\text { function }\end{array}$ & $13(4.5)$ & $4(0.9)$ & 0.001 \\
\hline \multicolumn{4}{|l|}{ Comorbidities } \\
\hline $\begin{array}{l}\geq 2 \text { primary malignan- } \\
\text { cies }\end{array}$ & $10(3.4)$ & $41(8.7)$ & 0.004 \\
\hline $\begin{array}{l}\text { PEG, Percutaneous Endos } \\
\text { Gastrostomy; SD, standar } \\
{ }^{*} \text { ( } \mathrm{N}=\text { number, \% = percen }\end{array}$ & $\begin{array}{l}\text { ic Gastrostom } \\
\text { eviation; BMI, } \\
\text { e) }\end{array}$ & $\begin{array}{l}\text { RG, Percutaneo } \\
y \text { mss index }\end{array}$ & \\
\hline
\end{tabular}

3.879]). After correction for age, gender, weight, diagnosis, and comorbidities in a multivariate logistic regression model, the difference between PEG and PRG was no longer significant $(P=0.481$, OR $0.771[0.374-1.590])$. Presence of CVA (OR 5.190 [2.139-12.597]) was associated with higher 30-day mortality. ALS (OR 0.231 [0.104-0.518]), a higher weight before placement (OR 1.002 [1.001-1.003]) and prophylactic placements in HNC were associated with lower 30-day mortality (OR 0.307 [0.212-0.444]).

\section{Procedure-related mortality}

Procedure-related mortality was $1.7 \%(n=5)$ for PEG and $0.4 \%$ $(n=2)$ for PRG $(P=0.113)$. Four PEG patients died due to aspiration pneumonia and one patient died from a massive gastric bleeding. Indications for PEG in these patients were HNC ( $n=$ $3)$, and CVA $(n=2)$. Two patients with aspiration pneumonia had experienced recurrent aspiration before PEG placement (one probably due to a tracheoesophageal fistula) and two were in poor condition after a major CVA.

Both deceased patients in the PRG group died from aspiration pneumonia and had severe comorbidities (liver cirrhosis resp. vascular dementia). One of them had been treated for aspiration pneumonia prior to gastrostomy.

\section{Complications}

Tube patency and tube-related complications

Overall complication rates are shown in $>$ Table 2 . Tube-related complications (including dislocation, obstruction, and leak and tube defects) were less frequent with PEG than with PRG, both within 30 days $(2.7 \%$ vs. $26.4 \%$ of patients, $P \leq 0.001$ and after 30 days $(8.6 \%$ vs. $31.5 \%, P \leq 0.001)$. Adjusted ORs after multivariate correction for baseline differences for PEG vs. PRG can be found in Supplementary Table 2. The overall adjusted ORs were $0.061(0.026-0.139)$ for early tube-related complications, and $0.252(0.155-0.411)$ for late tube-related complications. No multicollinearity or interactions were found.

In some patients, tube-related complications occurred more than once. The total number of tube-related complications are shown in Supplementary Table 3. In the PRG group, more than one tube-related complication occurred in 46 patients (9.8\%), in the PEG group in 17 patients (5.8\%, all PEG-j patients).

\section{Other complications}

Early major complications (including peritonitis, abscess, buried bumper, pneumonia) occurred in $3.4 \%$ of patients with PEG vs. $1.8 \%$ in PRG $(P=0.193)$. Late major complication rates were $5.4 \%$ with PEG vs. $7.1 \%(P=0.121)$ for PRG.

We observed one case of tumor seeding (HNC) occurring after a PRG procedure. A significantly higher rate of post-procedural pain was found in PRG (9.2\% vs. $3.8 \%$ in PEG). This was adequately treated with oral analgesics after the procedure.

Late skin deterioration (e. g. redness, mild granuloma formation) occurred more frequently in PEG patients (3.8\% vs. $0 \%$ in PRG, $P=0.005)$. Removal of the PEG was required in three patients due to skin deterioration. 
- Table 2 Complications (total no. of pts).

\section{Early Complications ( $\leq 30$ days)}

\begin{tabular}{|c|c|c|c|c|}
\hline & PEG $n=291$ (\%) & PRG $n=469(\%)$ & $P$ value & Significant OR [95\%Cl] \\
\hline Peristomal irritation (erythema) & $4(1.3)^{1}$ & $34(7.2)^{1}$ & $<0.001$ & $0.133[0.041-0.438]$ \\
\hline Peristomal infection & $5(1.7)^{1}$ & $7(1.5)^{1}$ & 0.808 & \\
\hline \multicolumn{5}{|l|}{ Pain } \\
\hline - Requiring conservative treatment & $11(3.8)$ & $43(9.2)$ & 0.005 & $0.389[0.197-0.768]$ \\
\hline - Requiring removal & $1(0.3)$ & $1(0.2)$ & 1 & \\
\hline Tube-related complications & $8(2.7)$ & $124(26.4)$ & $<0.001$ & $0.079[0.038-0.164]$ \\
\hline - Replacement through existing channel & $7(2.4)$ & $115(24.5)$ & $<0.001$ & $0.083[0.038-0.180]$ \\
\hline - Requiring new tube procedure & $1(0.3)$ & $9(1.9)$ & 0.064 & \\
\hline Bleeding & $6(2.0)$ & $6(1.3)$ & 0.400 & \\
\hline Peritonitis & $0(0)$ & $2(0.4)$ & 0.527 & \\
\hline Abscess & $0(0)$ & $2(0.4)$ & 0.527 & \\
\hline Aspiration pneumonia & $6(2.1)$ & $4(0.9)$ & 0.155 & \\
\hline \multicolumn{5}{|l|}{ Late complications ( $>30$ days) } \\
\hline \multicolumn{5}{|l|}{ Skin deterioration / granuloma } \\
\hline - Requiring conservative treatment & $11(3.8)$ & $0^{1}$ & 0.005 & $18.905[2.486-143.737]$ \\
\hline - Requiring removal & $3(1)$ & $0^{1}$ & 0.056 & \\
\hline \multicolumn{5}{|l|}{ Pain } \\
\hline - Requiring conservative treatment & $1(0.3)$ & $5(1.1)$ & 0.415 & \\
\hline - Requiring removal & $2(0.7)$ & $1(0.2)$ & 0.562 & \\
\hline Tube-related complications ${ }^{2}$ (no. pts) & $23(7.9)$ & $139(29.6)$ & $<0.001$ & $0.236[0.151-0.368]$ \\
\hline - Replacement through existing channel & $19(6.5)$ & $122(26)$ & $<0.001$ & $0.199[0.119-0.330]$ \\
\hline - Requiring new tube procedure & $6(2.0)$ & $26(5.5)$ & 0.026 & $0.359[0.146-0.882]$ \\
\hline Abscess & $1(0.3)$ & $2(0.4)$ & 1 & \\
\hline - Infection & $4(1.4)$ & $5(1.1)$ & 0.702 & \\
\hline Bleeding (requiring laparotomy) & $0(0.0)$ & $1(0.2)$ & 1 & \\
\hline Perforation (requiring laparotomy) & $0(0)$ & $1(0.2)$ & 1 & \\
\hline Tumor seeding & $0(0)$ & $1(0.2)$ & 1 & \\
\hline Buried bumper & $4(1.4)$ & $2(0.4)$ & 0.21 & \\
\hline
\end{tabular}

\section{Discussion}

Our study, involving 760 patients receiving either PEG or PRG for nutritional support, showed a higher procedural success rate for PRG compared to PEG. The overall 30-day mortality rate was significantly higher in the PEG group when compared to the PRG group. However, when corrected for age, gender, weight, diagnosis, and comorbidities, this difference was no longer significant. No differences in procedure-related mortality and complications were noted between both methods used.

\section{0-day mortality}

In literature, the reported 30-day mortality rates in PEG and PRG are comparable $[6,14,15]$. In our current analysis, multivariate logistic regression revealed no significant difference between PEG- and PRG-related 30-day mortality. It appears that a patient's underlying diseases and condition and not the procedure are predictive factors. Of particular note is that a significantly higher number of patients with CVA received PEG whereas a PRG was placed in a relatively high number of patients with HNC and ALS, which also might explain the differ- 
ence seen in the uncorrected analysis. Patients with prophylactic placement for HNC, ALS, and a higher BMI before placement had a lower risk of 30-day mortality. Patients with prophylactic placement had often been treated with curative intentions for their malignancies. Prognosis across the different patient groups undergoing gastrostomy also impacts 30-day mortality rates following gastrostomy placement. In ALS, rates of $3 \%$ to $15 \%$ are reported for both procedures [24-27], whereas median survival for motor neuron disease in general is 32 months following diagnosis [18]. In HNC, rates of $0 \%$ to $1 \%$ in PEG and $0 \%$ to $4 \%$ in PRG are reported $[18,29,30]$, with a 5 -year survival for all forms and stages of HNC being $50 \%$ [31]. In CVA, which was predictive for higher 30-day mortality in our study, rates of $11 \%$ to $14 \% 30$-day mortality have been reported [32]. Abuksis et al. reported a 30 -day mortality of $72 \%$ after PEG placement in hospitalized patients in general [33]. Whereas higher BMI was protective for 30-day mortality, age and comorbidities (such as DM, cirrhosis, cancer, chronic obstructive pulmonary disease) were not risk factors for 30-day mortality in our analysis. Previous literature, however, reported all these factors as predictive factors for 30-day mortality [34-38].

\section{Procedure-related mortality}

Procedure-related mortality was not significantly different between PRG and PEG. Our findings are in contrast to some previous studies, in which a higher procedure-related mortality after PRG vs. PEG has been reported with rates of $1 \%$ in PEG vs. $2 \%$ to $7 \%$ for PRG $[18,30,39]$. On the other hand, our data are in line with several others reports with mortality rates of $0 \%$ to $2 \%$ for both PEG and PRG $[6,24,40,41]$.

The question remains whether aspiration pneumonia within 7 days after gastrostomy placement is attributable to the procedure itself or also results from other precipitating factors associated with a higher risk of aspiration in general. In other words, aspiration pneumonia was already present at the time of gastrostomy. Many patients experienced recurrent aspirations prior to placement of a gastrostomy tube. In our group, this was the case with 33 patients $(4.3 \%)$ in total. In patients with procedure-related mortality with aspiration, incidence of recurrence was $50 \%$.

Risk of periprocedural aspiration is considered to be higher after use of sedatives. As a consequence, risk of aspiration is supposed to be lower for PRG as no sedatives are used [42, 43]. However, our analysis did not show significant differences. Higher pneumonia rates have also been reported after PRG [41]. Special concern exists for patients with ALS, in whom respiratory function often is impaired. Moreover, masseter muscle spasms might occur as well, in which the small insufflation tube in PRG can mostly be introduced, contrary to the endoscope in PEG [24]. In our hospital, PRG is first choice of treatment for patients with ALS for the above-stated reasons. A recent study by our group analyzing an ALS subgroup showed that conscious sedation in ALS is safe, even in patients with moderate pulmonary dysfunction [44].

\section{Tube-related complications}

Early tube-related complications (dislocation, leak, blockage) were more likely to occur with PRG than with PEG. This is probably due to the smaller diameter of the PRG tubes, $12 \mathrm{Fr}$ versus $15 \mathrm{Fr}$ in PEG, and the less solid fixation (with a locked pigtail) versus a more solid flange in PEG. The higher rate found in PRG (26.4\% early, $29.6 \%$ late) is comparable to previous literature, with rates reportedly between $21 \%$ and $40 \%$ [14, 30, 45, 46]. Tube dislocation appeared to be a risk factor for peritonitis due to leakage of gastric contents to the peritoneal cavity [14, $29,39]$ However, that could not be demonstrated in our study. The jejunal extension in PEG-J is known to dislocate more often than regular PEG, in up to $27 \%$ to $36 \%$ of cases, but other complication rates are comparable with PEG [47-49].

\section{Infectious complications}

In line with previous reports, low rates of minor and major infections were observed. Rates of early minor infection were $1.7 \%$ for PEG and $1.5 \%$ for PRG) [28]. However, higher rates of (minor) infection of $8 \%$ to $15 \%$ have been reported for PEG 1 , [40] and of $2 \%$ to $22 \%$ for PRG $[15,8,25]$. We cannot exclude that minor infections have been underreported, as our center is a tertiary referral center. Minor problems may have been treated at local hospitals or by general practitioners. This assumption is based on the exceptionally low numbers of these complications. At the start of data collection, we generally assumed patients always contacted us directly with complications, as this was specifically discussed with patients before placement of the gastrostomy. Therefore, due to the presumed underreporting, no solid conclusion regarding infectious complications can be drawn.

\section{Other complications}

Major complications did not differ between the two groups. Complication rates found in our study are largely comparable to data in the literature $[18,29,43,46]$. Post-procedural pain at the gastrostomy site is common, probably due to gastropexy 6]. Previous studies showed pain in $9.5 \%$ after PRG, which is in line with our current findings, showing minor pain in $9.2 \%$ shortly after PRG placement (compared to $3.8 \%$ in PEG). Of note is that pain post-PRG is generally easily treated with a short course of oral analgesics. Skin deterioration might also be prone to underreporting. According to our findings, this complication occurs more often with PEG than with PRG. Not all patients consider this a problem and it may not even be recognized. We therefore cannot provide definite conclusions with respect to skin deterioration. Literature rates therefore vary from $0 \%$ to $12 \%$ for PEG and $2.3 \%$ to $20 \%$ for PRG [14, 25 , 40].

\section{Tumor seeding}

At our institution, a PRG procedure is preferred over a PEG procedure for patients with oropharyngeal tumors. It may well be that the low incidence of tumor seeding in our study is related to avoidance of PEG placement as only eight patients who underwent PEG with an oropharyngeal tumor received the PEG 
before surgery. Remarkably, tumor seeding occurred in one patient after PRG, which has been reported only once in the literature [21]. Tumor seeding is considered to occur by transposition of tumor cells to the stomal site after pulling the gastrostomy tube alongside the tumor. Hematogenous spread of tumor cells might be another explanation. Adhesion of tumor cells at a gastrointestinal wound site after desquamation of tumor cells with subsequent swallowing $[19,20,50]$ has also been proposed.

Despite our remarkable finding, risk of tumor seeding in oropharyngeal tumors has been shown to be higher with PEG than with PRG, which is supported by numerous case reports [19, $21,51]$. For other HNC tumors, risk is comparable based on literature $[18,29,30]$ and data presented here.

\section{Limitations}

The current study has several limitations. First, due to the retrospective nature of the analysis, assignment to groups was empirical, based on clinical judgment and practical considerations, instead of randomization, thereby rendering the patient groups for PEG vs. PRG quite heterogeneous. We have included all patients in the specified periods and corrected all baseline confounders by multivariate logistic regression to minimize risk of bias. Missing data with regard to weight loss prior to placement and $\mathrm{BMI}$ were mostly encountered in patients with PEG from 2008 and 2009. Second, the inclusion period was longer for PEG, to reach comparable numbers. Baseline characteristics of 2008 and 2009 did not significantly differ from those for 2010 to 2016. Therefore, we do not expect that the longer inclusion period will have influenced the results.

Third, some patients received a PRG after PEG failure and vice versa. We do not expect this deviation from the intended intervention to influence outcomes, because we only assessed outcomes of successful procedures. Approximately $20 \%$ of "placement failures" were preventable if prior consultation with a gastroenterologist or radiologist had taken place (e.g. contraindications such as ascites, or inability to open their mouth). Fourth, mortality and complication rates are dependent on expertise of the radiologists/endoscopists and their supporting team. Local preference for PRG or PEG is dependent on availability, expertise, and teamwork. In an ideal setting, both techniques are available and can be used based on patient and team preference.

Finally, costs of both procedures may influence decisionmaking. However, precise estimation of costs is difficult. Not only procedural costs, but also follow-up, reinterventions, and complications should all be taken into account. The difficulty is emphasized by previous estimations, ranging from $\$ 591$ to $\$ 2400$ for PEG and $\$ 406$ to $\$ 4500$ for PRG $[40,43,52]$.

\section{Advice for daily practice}

Considering the significant 30-day mortality, neither PEG nor PRG placement should be considered in patients with a very short life expectancy who are in very poor condition (e.g. after a major (VA) [53]. Nasogastric or nasoduodenal feeding is an acceptable and relatively safe alternative [54] with no higher aspiration rates than in case of gastrostomy.
In patients who require prolonged enteral feeding, both PEG and PRG should be considered, taking into account local practice and existing expertise. The process of clinical decisionmaking should take into account aspects of the underlying disease and preferences of a team of experienced gastroenterologists and interventional radiologists. We advocate for a thorough selection for each individual patient, taking into account the risks and burdens of a gastrostomy and the type of gastrostomy. A multidisciplinary approach combined with a dedicated outpatient clinic (for assessment of the patient and provision of information) is highly recommended.

\section{Conclusion}

With respect to procedure-related and 30-day mortality, PEG and PRG compare equally. Underlying disease appears to be the most important predictive factor for mortality. PRG has a higher procedural success rate and placement is possible even in case of a stenotic or narrow esophagus. Tube-related complications and pain are less frequent after PEG compared to PRG. These complications are generally easily managed. The choice for PEG or PRG, therefore, should primarily be based on local facilities and expertise.

\section{Competing interests}

None

\section{References}

[1] Löser C, Aschl G, Hebuterne X et al. Consensus Statement; ESPEN guidelines on Artificial enteral nutrition - percutaneous endoscopic gastrostomy (PEG). Clin Nutr 2005; 24: 848-861

[2] Itkin M, DeLegge MH, Fang JC et al. Multidisciplinary practical guidelines for gastrointestinal access for enteral nutrition and decompression from the Society of Interventional Radiology and American Gastroenterological Association (AGA) Institute, with endorsement by Canadian Interventional Radiological Association (CIRA) and Cardiovascular and Interventional Radiological Society of Europe (CIRSE). J Vasc Interv Radiol 2011; 22: 1089-1106

[3] Preshaw RM. A percutaneous method for inserting a feeding gastrostomy tube. Surg Gynecol Obstet 1981; 152: 658-660

[4] Ho CS, Yee ACN, McPherson R. Complications of surgical and percutaneous nonendoscopic gastrostomy: review of 233 patients. Gastroenterol 1988; 95: $1206-10$

[5] Grant JP. Comparison of percutaneous endoscopic gastrostomy with Stamm gastrostomy. Ann Surg 1988; 207: 598-603

[6] Silas AM, Pearce LF, Lestina LS et al. Percutaneous radiologic gastrostomy versus percutaneous endoscopic gastrostomy: a comparison of indications, complications and outcomes in 370 patients. Eur J Radiol 2005; 56: 84-90

[7] Wollman B, D'Agostino HB. Percutaneous radiologic and endoscopic gastrostomy: a 3-year institutional analysis of procedure performance. Am J Roentgenol 1997; 169: 1551-1553

[8] Wollman B, D'Agostino HB, Walus-Wigle JR et al. Radiologic, endoscopic, and surgical gastrostomy: an institutional evaluation and meta-analysis of the literature. Radiology 1995; 197: 699-704 
[9] Neeff M, Crowder VL, Mclvor NP et al. Comparison of the use of endoscopic and radiologic gastrostomy in a single head and neck cancer unit. ANZ J Surg 2003; 73: 590-593

[10] Thornton F], Fotheringham T, Alexander M et al. Amyotrophic lateral sclerosis: Enteral nutrition provision - Endoscopic or radiologic gastrostomy? Radiology 2002; 224: $713-717$

[11] Eze N, Jefford JM, Wolf D et al. PEG and RIG tube feeding in Head and Neck patients: a retrospective review of complications and outcome. J Eval Clin Pract 2007; 13: 817-819

[12] Cosentini EP, Sautner T, Gnant M et al. Outcomes of surgical, percutaneous endoscopic, and percutaneous radiologic gastrostomies. Arch Surg (Chicago, III : 1960) 1998; 133: 1076-1083

[13] Allen JA, Chen R, Ajroud-Driss S et al. Gastrostomy tube placement by endoscopy versus radiologic methods in patients with ALS: a retrospective study of complications and outcome. Amyotroph Lateral Scler Frontotemporal Degener 2013; 14: 308 - 314

[14] La Nauze RJ, Collins K, Lyon S et al. Outcomes of percutaneous endoscopic gastrostomy versus radiologically inserted gastrostomy tube insertion at a tertiary hospital. ESPEN J 2012; 7: e144-e148

[15] Möller P, Lindberg CG, Zilli T. Gastrostomy by various techniques: evaluation of indications, outcome, and complications. Scand J Gastroenterol 2009; 34: 1050-1054

[16] Lipp A, Lusardi G. Systemic antimicrobial prophylaxis for percutaneous endoscopic gastrostomy. Cochrane Database of Syst Rev 2013: 11: CD005571

[17] Halpenny DF, Torreggiani WC. The Infectious complications of interventional radiology based procedures in gastroenterology and hepatology. J Gastrointestin Liver Dis 2011; 20: 71-75

[18] Grant DG, Bradley PT, Pothier DD et al. Complications following gastrostomy tube insertion in patients with head and neck cancer: a prospective multi-institution study, systematic review and metaanalysis. Clin Otolaryngol 2009; 34: $103-112$

[19] Coletti D, Genuit T, Ord R et al. Metastasis to the percutaneous endoscopic gastrostomy site in the patient with head and neck cancer: a case report and review of the literature. J Oral Maxillofac Surg 2006; 64: $1149-1157$

[20] Zhang L, Dean SA, Furth EE et al. Metastatic carcinoma to percutaneous endoscopic gastrostomy tube sites. A report of five cases. Am J Clin Pathol 2014; 141: 510 - 514

[21] Hawken RM, Williams RW, Bridger MW et al. Puncture-site metastasis in a radiologically inserted gastrostomy tube: case report and literature review. Cardiovasc Intervent Radiol 2005; 28: 377-380

[22] Gauderer MW, Ponsky JL, Izant R] et al. Gastrostomy without laparotomy: a percutaneous endoscopic technique. J Pediatr Surg 1980; 15 : $872-875$

[23] Sutcliffe J, Wigham A, McEniff $N$ et al. CIRSE Standards of Practice Guidelines on Gastrostomy. Cardiovasc Intervent Radiol 2016; 39: 973-987

[24] Chio A. Percutaneous radiological gastrostomy: a safe and effective method of nutritional tube placement in advanced ALS. J Neurol Neurosurg Psychiatry 2004; 75: 645-647

[25] McDermott C]. Gastrostomy in patients with amyotrophic lateral sclerosis (ProGas): A prospective cohort study. Lancet Neurol 2015; 14: $702-709$

[26] Blondet A, Lebigot J, Nicolas G et al. Radiologic versus endoscopic placement of percutaneous gastrostomy in amyotrophic lateral sclerosis: multivariate analysis of tolerance, efficacy, and survival. J Vasc Interv Radiol 2010; 21: 527-533

[27] Rio A, Ellis C, Shaw $C$ et al. Nutritional factors associated with survival following enteral tube feeding in patients with motor neurone disease. J Hum Nutr Diet 2010; 23: 408-415
[28] del Aguila MA, Longstreth WT Jr., McGuire V et al. Prognosis in amyotrophic lateral sclerosis: a population-based study. Neurology 2003; 60: $813-819$

[29] McAllister P, Maclver C, Wales C et al. Gastrostomy insertion in head and neck cancer patients: a 3 year review of insertion method and complication rates. Br J Oral Maxillofac Surg 2013; 51: 714-718

[30] Rustom IK, Jebreel A, Tayyab M et al. Percutaneous endoscopic, radiological and surgical gastrostomy tubes: a comparison study in head and neck cancer patients. J Laryngol Otol 2006; 120: 463-466

[31] Registry NC. Cijfers over Kanker [Numbers on cancer]. 2015: (cited 2017 August)

[32] Lichtman JH, Jones SB, Wang Y et al. Seasonal variation in 30-day mortality after stroke: teaching versus nonteaching hospitals. Stroke 2013; 44: $531-533$

[33] Abuksis G, Mor M, Segal N etal. Percutaneous endoscopic gastrostomy: high mortality rates in hospitalized patients. Am J Gastroenterol 2014; 95: 129-132

[34] Zopf $Y$, Konturek $P$, Nuernberger $A$ et al. Local infection after placement of percutaneous endoscopic gastrostomy tubes: A prospective study evaluating risk factors. Can J Gastroenterol 2008; 22: 987 - 991

[35] Barbosa M, Magalhaes J, Marinho C et al. Predictive factors of early mortality after percutaneous endoscopic gastrostomy placement: The importance of C-reactive protein. Clin Nutr ESPEN 2016; 14: 19 23

[36] Richter-Schrag HJ, Richter S, Ruthmann O et al. Risk factors and complications following percutaneous endoscopic gastrostomy: A case series of 1041 patients. Can J Gastroenterol 2011; 25: 201-206

[37] Lang A, Bardan E, Chowers Y et al. Risk factors for mortality in patients undergoing percutaneous endoscopic gastrostomy. Endoscopy 2004; 36: $522-526$

[38] Lang EK, Allaei A, Abbey-Mensah G et al. Percutaneous radiologic gastrostomy: results and analysis of factors contributing to complications. J La State Med Soc 2013; 165: 254 - 259

[39] Elliott LA, Sheridan MB, Denyer M et al. PEG - Is the E Necessary? a comparison of percutaneous and endoscopic gastrostomy Clin Radiol 1996; 51: $341-344$

[40] Galaski A, Peng WW, Ellis M et al. Gastrostomy tube placement by radiological versus endoscopic methods in an acute care setting: A retrospective review of frequency, indications, complications and outcomes. Can J Gastroenterol 2009; 23: 109-114

[41] Laskaratos FM, Walker M, Walker M et al. Predictive factors for early mortality after percutaneous endoscopic and radiologically-inserted gastrostomy. Dig Dis Sci 2013; 58: 3558-3565

[42] Laasch HU, Wilbraham L, Bullen K et al. Gastrostomy insertion: comparing the options-PEG, RIG or PIG? Clin Radiol 2003; 58: 398-405

[43] Wollman B, D'Agostino HB, Walus-Wigle JR et al. Radiologic, endoscopic, and surgical gastrostomy: an institutional evaluation and meta-analysis of the literature. Radiology 1995; 197: 699-704

[44] Strijbos D, Hofstede J, Keszthelyi D et al. Percutaneous endoscopic gastrostomy under conscious sedation in patients with amyotrophic lateral sclerosis is safe: an observational study. Eur J Gastroenterol Hepatol 2017; 29: $1303-1308$

[45] MacLean AA, Alvarez NR, Davies JD et al. Complications of percutaneous endoscopic and fluoroscopic gastrostomy tube insertion procedures in 378 patients. Gastroenterol Nurs 2007; 30: 337 - 341

[46] Neeff M, Crowder VL, Mclvor NP et al. Comparison of the use of endoscopic and radiologic gastrostomy in a single head and neck cancer unit. ANZ J Surg 2003; 73: 590-593

[47] Fan AC, Baron TH, Rumalla A et al. Comparison of direct percutaneous endoscopic jejunostomy and PEG with jejunal extension. Gastrointest Endosc 2002; 56: $890-894$ 
[48] Palmer LB, McClave SA, Bechtold ML et al. Tips and tricks for deep jejunal enteral access: modifying techniques to maximize success. Curr Gastroenterol Rep 2014; 16: 409

[49] DiSario JA, Foutch PG, Sanowski RA. Poor results with percutaneous endoscopic jejunostomy. Gastrointest Endosc 1990; 36: 257-260

[50] Cappell MS. Risk factors and risk reduction of malignant seeding of the percutaneous endoscopic gastrostomy track from pharyngoesophageal malignancy: a review of all 44 known reported cases. Am J Gastroenterol 2007; 102: $1307-1311$

[51] Sinapi I, Navez B, Hamoir M et al. Seeding of the percutaneous endoscopic gastrostomy site from head and neck carcinoma: case report and review of the literature. Head Neck 2013; 35: E209-E212
[52] Barkmeier JM, Trerotola SO, Wiebke EA et al. Percutaneous Radiologic, surgical endoscopic, and percutaneous endoscopic gastrostomy/ gastrojejunostomy: comparative study and cost analysis. CardioVasc Intervent Radiol 1998; 21: $324-328$

[53] Wilcox CM. Gastrostomy tubes and quality of life: is the glass half empty or half full? Clin Gastroenterol Hepatol 2017; 15: 998 - 999

[54] Gomes CA Jr., Andriolo RB, Bennett C et al. Percutaneous endoscopic gastrostomy versus nasogastric tube feeding for adults with swallowing disturbances. Cochrane Database Syst Rev 2015; 05: CD008096 